\title{
Rise and Fall of Therapeutic Hypothermia in Low-Resource Settings: Lessons from the HELIX Trial: Correspondence
}

\author{
Nishad Plakkal ${ }^{1}$ D $\cdot$ Srinivas Murki ${ }^{2}$
}

Received: 2 August 2021 / Accepted: 13 September 2021 / Published online: 25 September 2021

(c) Dr. K C Chaudhuri Foundation 2021

To the Editor: We would like to highlight serious issues in a review article by Sudhin Thayyil (corresponding author) and others in your esteemed journal [1].

The authors of the review claim that the HELIX trial "has set a new benchmark for clinical trials in neonatal medicine in LMIC and greatly elevated the bar...of the rigor of research..." These claims-based on a paper which was still in press at the time and has since been published [2] - bring to mind the well-known cautionary tale of the emperor's fine clothes.

However, we are more concerned by the condescending tone that the authors have expressed towards what they call "LMIC clinicians"-presumably including all clinicians and researchers in India-and unsubstantiated accusations against highly respected institutions and researchers in our country. The authors claim that "in high-income countries, randomized controlled trials are taken extremely seriously," while "most LMIC trials are conducted by postgraduate students with little prior research experience," with no evidence to back these broad and blatantly prejudicial statements.

We were shocked to read the authors' allegation that "Thomas and colleagues from Christian Medical College Vellore marketed phase change material in India...with claims of it being a lifesaving and innovative device." Common sense dictates that extraordinary claims require extraordinary evidence. The authors offer none. They cast doubt on the reliability of 6 clinical trials over the last decade from Jawaharlal Institute of Postgraduate Medical Education \& Research, Pondicherry because mortality varied widely in the "usual care groups." Variability in referral patterns, case

Nishad Plakkal

plakkal@gmail.com

1 Department of Neonatology, Jawaharlal Institute of Postgraduate Medical Education and Research (JIPMER), Puducherry 605006, India

2 Department of Neonatology, Children Hospital, Paramitha Women \&, Hyderabad, Telangana, India mix (including proportion of infants with severe encephalopathy), temporal trends, and random chance can all cause large variations in mortality, especially in small trials. However, the review authors seem to focus on the theme of all LMIC trial data being fraudulent.

The authors rightly state that " "white savior' approaches rarely benefit the local population nor help in local capacity building in LMIC." However, just a few sentences laterand apparently without any sense of irony-they offer the white savior approach of "LMIC clinicians" undertaking $\mathrm{PhD}$ in the UK or training in Western programs to strengthen academic capacity in LMIC. We feel that simplistic solutions like these are no likelier to improve academic capacity than training LMIC chefs in Western kitchens is likely to eradicate global hunger.

IJP has a reputation for publishing high-quality articles. Since this review shows a glaring lack of professional courtesy and attempts to malign a large body of research from India and other LMIC based on meagre data, we request the editors to strongly consider retracting it.

\section{Declarations}

Conflict of Interest None.

\section{References}

1. Krishnan V, Kumar V, Shankaran S, Thayyil S. Rise and fall of therapeutic hypothermia in low-resource settings: lessons from the HELIX trial. Indian J Pediatr. 2021. https://doi.org/10.1007/ s12098-021-03861-y.

2. Thayyil S, Pant S, Montaldo P, et al. HELIX consortium. Hypothermia for moderate or severe neonatal encephalopathy in lowincome and middle-income countries (HELIX): a randomized controlled trial in India, Sri Lanka, and Bangladesh. Lancet Glob Health. 2021;9:e1273-85.

Publisher's Note Springer Nature remains neutral with regard to jurisdictional claims in published maps and institutional affiliations. 